\title{
Serum progesterone and serum $\beta$-HCG levels in first trimester threatened abortion
}

Mohamed Fawzy Saleh Mohamed ${ }^{1 *}$ MSc; Abdallah Khalil Ahmed ${ }^{1}$ MD; Samir Kamis Galal ${ }^{1}$ MD

\author{
*Corresponding Author: \\ Mohamed Fawzy Saleh Mohamed \\ dr.mohamedfawzy22@gmail.com
}

Received for publication May 10, 2020; Accepted October 16, 2020; Published online October 16, 2020.

Copyright 2020 The Authors published by Al-Azhar University, Faculty of Medicine, Cairo, Egypt. All rights reserved. This an openaccess article distributed under the legal terms, where it is permissible to download and share the work provided it is properly cited. The work cannot be changed in anyway or used commercially.

doi: 10.21608/AIMJ.2020.29940.1223

${ }^{1}$ Obstetrics and Gynecology Department, Faculty of Medicine, Al-Azhar University,Cairo,Egypt.

\begin{abstract}
Background: Spontaneous threatened abortion is a painful or painless vaginal bleeding from a closed cervix in the condition of positive embryo cardiac pulsations in the first 20 weeks of pregnancy. Most of pregnant women look for urgent obstetrician consultation in early pregnancy because of sudden abdominal pain with or without vaginal bleeding .

Aim of the work: aimed to declare the relation between maternal serum progesterone level and serum BHCG level in case of threatened abortion and their prediction role of the end result of that abortion.

Patients and Methods: : The study was carried out at El Hussien and Om El Masreen hospitals. 200 patients on the $5^{\text {th }}-12^{\text {th }}$ week of gestation with first trimester threatened abortion were included in our study

Results: Regarding patient 's age, GA, HB and BMI, there is showed no significant difference between the groups. In our study, BHCG and progesterone are markedly acceptable to anticipate abortion end result with a cutoff value of B-HCG and Progesterone which was (18153 $\mathrm{mIU} / \mathrm{ml}, 23.5 \mathrm{ng} / \mathrm{ml})$. The sensitivity, specificity for B_HCG at 18153 $\mathrm{mIU} / \mathrm{ml}$ were $100 \%$ and $98.2 \%$, respectively, for Progesterone at 23.5 $\mathrm{ng} / \mathrm{ml} 83 \%$ and $89 \%$ respectively.

Conclusion: In case of threatened abortion, using BHCG to anticipate the end result is more reliable than progesterone. Moreover, The assaying of BHCG and progesterone together does not add any benefits on sensitivity, while specificity increased from $98.2 \%$ to $100 \%$.
\end{abstract}

Keywords: Progesterone; B_H.C.G; Threatened abortion

Disclosure: The authors have no financial interest to declare in relation to the content of this article. The Article Processing Charge was paid for by the authors.

Authorship: All authors have a substantial contribution to the article.

\section{INTRODUCTION}

Abortion is a fetus delivery before reaching $500 \mathrm{~g}$ or the age of viability. The age of viability differs between countries according to accompanying resources and supplies. The threatened abortion is detected, if pregnant woman has a vaginal bleeding in case of a closed cervix during the first 20 weeks of pregnancy. ${ }^{1}$ Progesterone facilitates implantation by preparing and supporting endometrial building process and it is helpful in quieting the uterus or minimizing the bleeding that occur with implantation and provide an important environmental support for implantation. Increased Progesterone production has a great effect on uterine smooth muscle by suppressing its activity and contractility. Furthermore, its significant role in suppressing the rejection of the trophoblasts by inhibit the immunological rejection of newly implanted embryo. $^{2}$ B_HCG secreted mainly by the syncytiotrophoblasts of the placenta after successful implantation and it is responsible for continuation of pregnancy. It has a main role in support and maintenance of the function of the corpus luteum by maintain progesterone release from the day after implantation, by that time serum B_HCG test may be positive. $^{3}$

This study aimed to declare the relation between maternal serum progesterone level and serum B_H.C.G level in patients with threatened abortion at gestational age 5-12 weeks and their relation to outcome of abortion.

\section{PATIENTS AND METHODS}

The study was carried out at El Hussien and Om El Masreen hospitals during the period from June 2017 to November 2019. 200 patients on the $5^{\text {th }}-12^{\text {th }}$ week of gestation with first trimester threatened abortion were included in our study. All pregnant women who were included in our study signed an informed written consent to clarify their agreement to be enrolled in our study. Pregnant women who were diagnosed with twin pregnancy, ectopic pregnancy, embryonic demise, induced abortion, prior treatment with progesterone or B_HCG, diabetic patient , vesicular mole and bleeding tendency diseases were excluded in our study. All cases were subjected to history taking including personal history (name, age, parity and educational level), menstrual history (L.M.P, menarche , nature of menses), Obstetric 
history (number of parity, abortion, living children and history of previous sections). General examination was done to exclude general causes of bleeding while pelvic and speculum examination was done to exclude other local causes of vaginal bleeding as cervical erosion and to examine cervix opened or closed. Trans_ vaginal ultrasonographic scanning was done at the first presentation to check fetal viability, assess measurements, retroplacental hemorrhage and placenta previa. We assay progesterone and B_HCG levels at the time of presentation by venous blood samples collection from all cases. All cases were followed up every two weeks by ultrasound to assess fetal viability and measurements till $20^{\text {th }}$ week gestation and according the outcome they were divided in two groups the aborted group and the continued group.

Statistical analysis:

SPSS version 24 was our chosen version. MD and SD were used to analyze data , while frequency and percentage were used with qualitative data. We compare between the continued and aborted group by Student t test, while comparing non parametric data corrected chi square was used. Our cutoff value of serum progesterone and serum beta HCG was detected by receiver operator characteristic curve (ROC) analysis.

\section{RESULTS}

This prospective study was conducted on two hundred pregnant women on the 5- th 12th week of gestation with threatened abortion. The abortion rate is $27.5 \%$ (55 aborted cases ) till the 20th week of gestation. We divided the patients into two groups aborted group and continued group.

\begin{tabular}{|c|c|c|c|c|}
\hline Variables & $\begin{array}{c}\text { Aborted } \\
(n=55)\end{array}$ & $\begin{array}{c}\text { Continued } \\
(n=139)\end{array}$ & $\mathbf{T}$ & $\mathbf{P}$ \\
\hline $\begin{array}{c}\text { Age } \\
\text { (years) } \\
\text { Mean } \pm S D\end{array}$ & $\begin{array}{c}29.62 \pm \\
3.82\end{array}$ & $\begin{array}{c}29.12 \pm \\
4.12\end{array}$ & .781 & .436 \\
\hline $\begin{array}{c}\text { GA } \\
\text { (weeks) } \\
\text { Mean } \pm S D\end{array}$ & $\begin{array}{c}10.28 \pm \\
1.87\end{array}$ & $\begin{array}{c}10.64 \pm \\
1.03\end{array}$ & 1.03 & .302 \\
\hline $\begin{array}{c}\text { Hb }(g / d l) \\
\text { Mean } \pm S D\end{array}$ & $\begin{array}{c}9.89 \pm \\
1.75\end{array}$ & $\begin{array}{c}10.12 \pm \\
1.25\end{array}$ & 1.73 & .085 \\
\hline $\begin{array}{c}\text { BMI } \\
\left(\mathrm{kg} / \mathrm{m}^{2}\right) \\
\text { Mean } \pm S D\end{array}$ & $\begin{array}{c}28.85 \pm \\
3.66\end{array}$ & $29.3 \pm 3.39$ & .819 & .413 \\
\hline
\end{tabular}

Table 1: Demographic and clinical variables distribution according to aborted or continued. This table revealed no considerable difference found regarding age, GA, hemoglobin and BMI between the aborted and continued groups.

\begin{tabular}{|c|c|c|c|c|}
\hline Variables & $\begin{array}{c}\text { Aborted } \\
(\boldsymbol{n}=55)\end{array}$ & $\begin{array}{c}\text { Continued } \\
(\boldsymbol{n}=\mathbf{1 3 9 )}\end{array}$ & $\mathbf{T}$ & $\mathbf{P}$ \\
\hline $\begin{array}{c}\boldsymbol{\beta} \text {-hCG } \\
(\text { mlU/ml) } \\
\text { Median } \\
\text { Range }\end{array}$ & $\begin{array}{c}7950 \\
1287-\end{array}$ & $\begin{array}{c}112253 \\
17982-\end{array}$ & $\mathbf{2 6 1 . 5}$ & $<\mathbf{0 . 0 0 1}$ \\
\hline $\begin{array}{c}\text { Progesterone } \\
(\mathrm{ng} / \mathrm{mL}) \\
\text { Mean } \pm S D\end{array}$ & $\begin{array}{c}25.14 \pm \\
8.33\end{array}$ & $\begin{array}{c}27.87 \pm \pm \\
5.12\end{array}$ & $\mathbf{2 . 5 7}$ & $\mathbf{. 0 1 2}$ \\
\hline
\end{tabular}

Table 2: B_hCG and Progesterone distribution according to aborted or continued. Regarding median B_hCG levels were significantly lower among aborted women compared to those who continued pregnancy. Meanwhile, mean progesterone levels were low significant between the groups.
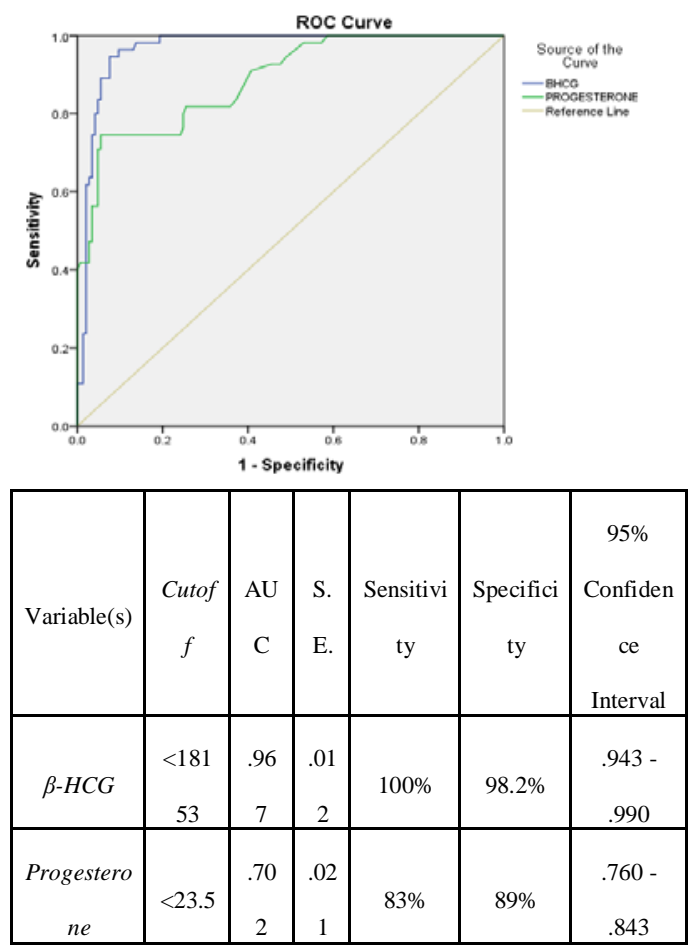

Fig 1: ROC curve for $\beta$-HCG and Progesterone for predicting abortion. The ROC curve showed that the cut off level of $\beta$-HCG 18153 gave 100\% sensitivity and specificity was $98.2 \%$ and cut off level of Progesterone 23. 5 gave $83 \%$ sensitivity and specificity was $89 \%$.

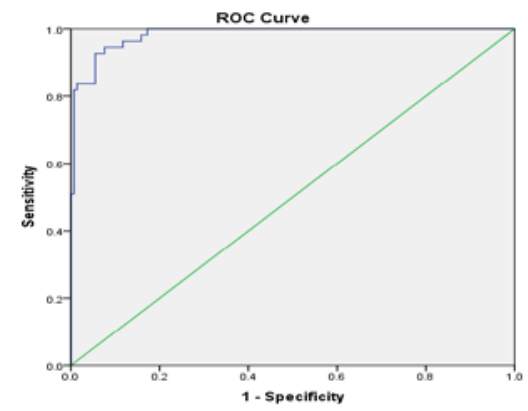




\begin{tabular}{|c|c|c|c|c|c|c|}
\hline Variable & $\begin{array}{c}\mathrm{AU} \\
\mathrm{C}\end{array}$ & E. & Sig. & $\begin{array}{c}\text { Sensiti } \\
\text { vity }\end{array}$ & $\begin{array}{c}\text { Specifi } \\
\text { city }\end{array}$ & $\begin{array}{c}95 \% \\
\text { Confide } \\
\text { nce } \\
\text { Interval }\end{array}$ \\
\hline $\begin{array}{c}\beta \text {-hCG \& } \\
\text { Progester } \\
\text { one }\end{array}$ & $\begin{array}{c}.98 \\
3\end{array}$ & 07 & $\begin{array}{c}<0.0 \\
01\end{array}$ & $100 \%$ & $100 \%$ & $\begin{array}{c}.970- \\
.997\end{array}$ \\
\hline
\end{tabular}

Fig 2: ROC curve for investigated B_H.C.G and Progesterone together for predicting abortion. The ROC curve showed that progesterone and $\beta$-H.C.G combined together rises specificity up to $100 \%$.

\begin{tabular}{|c|c|c|c|c|c|c|}
\hline & \multirow{2}{*}{$\beta$} & \multirow{2}{*}{$\begin{array}{c}\text { S.E } \\
\cdot\end{array}$} & \multirow{2}{*}{ Sig. } & \multirow{2}{*}{ B } & \multicolumn{2}{|c|}{$\begin{array}{c}\text { 95\% C.I. for } \\
\text { B } \\
\end{array}$} \\
\hline & & & & & $\begin{array}{c}\text { Lowe } \\
r\end{array}$ & $\begin{array}{c}\text { Uppe } \\
r\end{array}$ \\
\hline $\begin{array}{c}\text { Age (by } \\
\text { increasin } \\
\text { g } 5 \text { yr) }\end{array}$ & .098 & .047 & .185 & 1.132 & .052 & 1.041 \\
\hline BMI & .056 & .056 & .315 & 1.058 & .948 & 1.181 \\
\hline $\begin{array}{c}\boldsymbol{\beta} \text {-hCG } \\
(<18153) \\
\end{array}$ & .969 & .158 & $<0.001$ & 1.951 & 1.732 & 3.012 \\
\hline $\begin{array}{c}\text { Progester } \\
\text { one } \\
(<23.5) \\
\end{array}$ & .481 & .144 & .094 & 1.618 & 1.375 & 1.904 \\
\hline Constant & -13.710 & 2.229 & $<0.001$ & .000 & & \\
\hline
\end{tabular}

Table (3): Logistic Regression model for abortion. The table showed that there is significant risk for abortion in case of patients with decreasing in B_H.C.G level.

\section{DISCUSSION}

Miscarriage is an anxious thought faced by women who look for to be a mother. Miscarriage is pregnancy termination before fetus reach the age of viability. Up to $20 \%$ of all pregnant women, their pregnancy would ended by miscarriage and most of them occurred during the first trimester. ${ }^{4}$ Early vaginal bleeding could be a predictor for miscarriage. However, there were different risk of miscarriage based on reported duration and amount of bleeding and accompanying pain symptoms. ${ }^{5}$

Progesterone and B_HCG were consider as reliable single markers because of their potential prediction of miscarriage. Progesterone is one of ovarian steroid hormones secreted by the ovary and markedly related to the continuation and stabilization of pregnancy. This hormone plays important role for preparing uterus for embryo implantation. The other importance of progesterone is inhibition of uterus contraction and suppression of the maternal immune system. ${ }^{6}$ HCG promotes progesterone production by corpus luteal cells, promotes angiogenesis in uterine hypertrophy; aids in suppressing maternal immunity and cripples phagocytes action on implanted embryo and placental formation; increases uterine growth parallel to fetal growth; Facilitates implantation and enhances maturation of fetus organs during fetal life. ${ }^{7}$. Increased progesterone levels means a well functional corpus luteum and a healthy growing placenta. Viable pregnancy have been associated with more than $55 \mathrm{nmol} / \mathrm{L}$ serum progesterone levels, meanwhile low levels less than $30 \mathrm{nmol} / \mathrm{L}$ signals to incoming pregnancy failure. ${ }^{8}$

Serum progesterone concentration $<5 \mathrm{ng} / \mathrm{ml}$ reflect ongoing pregnancy failure, whilst healthy pregnancy is more related to values $>20 \mathrm{ng} / \mathrm{ml} .{ }^{9}$ In our study we found that $\beta$-HCG levels were significantly lower among aborted women compared to those who continued pregnancy, meanwhile progesterone levels were low significant between the groups. In agreement with Osmanağaoğlu et al ${ }^{10}{ }^{10}$ study, who revealed that $\beta$-HCG levels were detected significantly lower in the aborted women than that of the group where no abortion was detected. Also, we revealed that $B_{-}$HCG and progesterone are significant in predicting pregnancy out come with a cutoff value of B_HCG and Progesterone which was (18153 mIU/ml ,23.5 ng/ml). for B_HCG at 18153 $\mathrm{mIU} / \mathrm{ml}$ were $100 \%$ and $98.2 \%$, respectively meanwhile, for Progesterone at $23.5 \mathrm{ng} / \mathrm{ml} 83 \%$ and $89 \%$ respectively. and this is supported by the results of by (Maged and Mostafa ${ }^{11}$; Kim et al. ${ }^{12}$; Darwish et al. ${ }^{13}$; Duan et al. ${ }^{14}$, and Al-Sebai et al. ${ }^{15}$ ).

Moreover, we warranted that $\beta$-HCG is considered as an independent factor on miscarriage. Also, we have noticed a significant positive correlation between $\beta$ HCG and progesterone. This result agreed with that reported by Al-Sebai et al. ${ }^{15}$ who studied the role of B_HCG measurement in normal pregnant women and women who complained of vaginal bleeding in their first eighteen weeks of pregnancy revealed that a single serum B_HCG measurement is greatly acceptable in the prediction of prognosis of vaginal bleeding in early 18 weeks of gestation.

In study of Darwish et al. ${ }^{13}$ who investigated using progesterone in cases with recurrent abortions to predict pregnancy outcome, they revealed that no relevant relation between progesterone and pregnancy outcome with a $43 \%$ sensitivity and 50\% specificity. Also, Kim et al. ${ }^{12}$ in comparison between B_HCG, progesterone and inhibin A for prediction of threatened abortion outcome found that the single measurement of serum HCG is sufficient meanwhile, the ordinary assessment of inhibin A serum and progesterone levels seems to be unjustifiable in these patients to predict pregnancy outcomes. Meanwhile, Verhaegen et al. ${ }^{16}$ in their recent meta-analysis study revealed that the single marker strategy for predicting the prognosis of threatened miscarriage is not preferred rather than the combination of serum progesterone with serum B_H.C.G which is more reliable. In the contrary, Lo and Rajuddin ${ }^{17}$ use the cut-off point of progesterone 
to a level of $19.5 \mathrm{ng} / \mathrm{dl}$ gave the best sensitivity and specificity. Also Abdelazim et al. ${ }^{18}$ which found a 20 $\mathrm{ng} / \mathrm{dl}$ as a cut-off point had $95.1 \%$ sensitivity and $98.9 \%$ specificity to predict viable and non-viable pregnancy. Duan et al. ${ }^{14}$ concluded that there is significant relation between measuring B_HCG and progesterone in predicting outcome of threatened abortion and when using together shows great improvement over a single test. Depend on our findings, the single measurement of B_H.C.G give the best sensitivity, specificity and the best prognosis rather than progesterone. Moreover, The Combination does not add any benefit on sensitivity ,while specificity increased from $98.2 \%$ to $100 \%$.

\section{CONCLUSION}

We revealed that B_HCG is considered as an independent factor on miscarriage. Also, we have noticed a significant positive correlation between B_HCG and progesterone . In case of threatened abortion, using B_HCG to anticipate the end result is more reliable than progesterone with a cutoff value of B_HCG $18153 \mathrm{mIU} / \mathrm{ml}$ (with sensitivity 100\% and specificity $98.2 \%$ ), Progesterone $23.5 \mathrm{ng} / \mathrm{ml}$ ( with sensitivity $83 \%$ and specificity $89 \%$ ). Depend on our results, the single measurement of B_HCG gave the best sensitivity, specificity and the best prognosis rather than progesterone. Moreover, The Combination of B_HCG and progesterone does not add any benefits on sensitivity, while specificity increased from $98.2 \%$ to $100 \%$.

\section{REFERENCES}

1. Ahmed M and Walaa AI : Biochemical and ultrasonographic predictors of outcome in threatened abortion. Middle East Fertility Society Journal. 2013 ; 18: 177-81.

2. Speroff, L., Glass, Kase and N.G: The endocrinology of pregnancy. In Clinical Gynecologic Endocrinology and Infertility. Williams and Wilkins, Baltimore, MD.(8th edition).2011;1:40-65.

3. Speroff, L., Glass, R.H. and Kase, N.G: The endocrinology of pregnancy. In Clinical Gynecologic Endocrinology and Infertility. Williams and Wilkins, Baltimore, MD.(7 th edition).2005;1:275-335.

4. Miller D: Assessment and management of miscarriage. New Zealand Family Physician, 35: 2008.

5. Hasan R, Baird DD, Herring AH, Olshan AF, Jonsson Funk ML, Hartmann KE: Association between first-trimester vaginal bleeding and miscarriage. Obstet Gynecol. 2009;114(4):860-7.

6. Hanita $\mathrm{O}$ and Hanisah $\mathrm{AH}$ : Potential use of single measurement of serum progesterone in detecting early pregnancy failure. Malaysian J Pathol.2012; 34(1): $41-6$.

7. Laurance A cole: Biological functions of hCG and hCG-relatedmolecules. Cole Reproductive Biology and Endocrinology.2010; 8:102.

8. Orasanu B, Jackson KV and Hornstein MD : Effects of culture medium on HCG concentrations and their value in predicting successful IVF outcome. Reprod Biomed Online; 12(5):590-8.

9. Cunningham FG, Kenneth Jl, Steven LB, et al : Implantation ,Embryogenesis ,and Placental Development .Williams Obstetrics (23rdedition) . McGraw-Hill.2010; 3 (3): 36-72.

10. Osmanağaoğlu MA, Karahan SC, Aran T: The Diagnostic Value of $\beta$-Human Chorionic Gonadotropin, Progesterone, and IschemiaModified Albumin and Their Combined Use in the Prediction of First Trimester Abortions. Int Sch Res Notices. 2014;2014:846531.

11. Maged AM, AlMostafa W: Biochemical and ultrasonographic predictors of outcome in threatened abortion. Middle East Fertil Soc J, 18 (2013), pp. 177-81.

12. Kim SJ, Lee C and Kwon SY: Studying changes in the incidence, diagnosis and management of GTD: the south Korean model. J Reprod Med .2004;49: 643.

13. Darwish A, Ghorab N, Hazem E, Manal K and Ahmed S: Biochemical markers for prediction of pregnancy outcome in cases of recurrent pregnancy loss. Middle East Fertil Soc, 10 (2005): 59-62.

14. Duan L, Denglu Y and Weiyue Z:Predictive power progesterone combined with beta human chorionic gonadotropin measurements in the outcome of threatened miscarriage. Arch Gynecol Obstet.2011;33 (283): 431-5.

15. Al-Sebai MA, Diver M and Hipkinw L : The role of a single free p-human chorionic gonadotrophin measurement in the diagnosis of early pregnancy failure and the prognosis of fetal viability. Human Reproductio.1995; vol. 11 no.4 pp.881-8.

16. Verhaegen J, Gallos ID and van Mello NM: Accuracy of single progesterone test to predict early pregnancy outcome in women with pain or bleeding: meta-analysis of cohort studies. BMJ. 2012;345:e6077.

17. Lo E, Rajuddin R:The Accuracy of single progesterone , single hcg, and their combination measurement in predicting early misscarriage ASPIRE conference proceedings.

18. Abdelazim IA, Elezz AA, Elsherbiny M : Relation between single serum progesterone assay and viability of the first trimester pregnancy. Springerplus. 2012;1(1):80. doi:10.1186/21931801-80. 